\title{
What Ignorance Could Not BE
}

\author{
EKATERINA KUBYSHKINA \\ Centre for Logic, Epistemology and the History of Science, State University of Campinas, BRAZIL \\ ekubysh@unicamp.br \\ Mattia Petrolo \\ Center for Natural and Human Sciences, Federal University of ABC, BRAZIL \\ mattia.petrolo@ufabc.edu.br
}

\begin{abstract}
In the current debate there are two epistemological approaches to the definition of ignorance. The Standard View defines ignorance simply as not knowing, while the New View defines it as the absence of true belief. We argue that both views provide necessary, but not sufficient conditions for ignorance, and thus do not constitute satisfactory definitions for such a notion.
\end{abstract}

Keywords: Ignorance $\bullet$ definition of ignorance $\bullet$ standard view of ignorance $\bullet$ new view of ignorance $\bullet$ mental state

RECEIVED: $15 / 12 / 2019$

REVISED: 17/04/2020

ACCEPTED: $14 / 05 / 2020$

\section{Introduction}

In recent years, various attempts have been made to elucidate the notion of ignorance. Traditionally, ignorance is considered simply as the absence of knowledge. Such a view is endorsed, among others, by Zimmerman (1988), Driver (1989), Fields (1994), Le Morvan (2011, 2012, 2013) and is today dubbed the Standard View (see Le Morvan \& Peels (2016)). A different definition considers that ignorance corresponds to the absence of true belief. This position is called the New View and is defended, among others, by Goldman (1986), Goldman \& Olsson (2009), Guerrero (2007), van Woudenberg (2009), and Peels (2010, 2011, 2012, 2019a). These two definitions can be recast as stating necessary and sufficient conditions for an agent $S$ to be ignorant of a given proposition $p$, as follows:

(SV) $S$ is ignorant that $p$ if and only if it is not the case that $S$ knows $p$;

(NV) $S$ is ignorant that $p$ if and only if it is not the case that $S$ has a true belief that $p$.

The crucial difference between the two positions is usually presented (see Le Morvan \& Peels (2016)) as depending on the acceptance (Standard View) or rejection 
(New View) of two specific situations as genuine cases of ignorance. First, the case where justified true belief does not imply knowledge (corresponding to the so-called Gettier examples, see Gettier (1963)). Second, the case of false propositions.

Despite these differences, both views share a common ground: they aim to provide a definition in terms of absence. In what follows, we focus on this point and argue that both the Standard View and the New View provide necessary, but not sufficient, conditions for ignorance.

\section{The bowling ball argument}

DeNicola (2017) noticed that the Standard View suffers from what he calls a category mistake. First, we present his argument and, secondly, we show how to adapt it to the New View.

Consider the following false proposition:

(a) A bowling ball knows that $p$.

The fact that (a) is false implies that the following is true:

(b) A bowling ball does not know that $p$.

But for the Standard View, (b) is sufficient to conclude that the following is true:

(c) A bowling ball is ignorant of $p$.

This example can be adapted, mutatis mutandis, to the definition provided by the New View.

Consider the following false proposition:

(a') A bowling ball has a true belief that $p$.

The fact that (a') is false implies that the following is true:

(b') A bowling ball does not have a true belief that $p$.

But for the New View (b') is sufficient to conclude that the following is true:

(c') A bowling ball is ignorant of $\mathrm{p}$.

In both cases, a bowling ball turns out to be ignorant, which is prima facie a counterintuitive and paradoxical situation. What is wrong with both (c) and (c')? Following DeNicola (2017), p. 17, the problem lies in ascribing "to an object of a certain category something that is logically inappropriate for objects of that category." 
An ascription of ignorance to an inanimate object misses the target, as it were, both in the case of the Standard View and the New View.

Propositions (c) and (c') are direct consequences of (b) and (b') respectively, and (b) and (b') seem less counterintuitive than (c) and (c'), at least at first sight. Propositions (b) and (b') express absence of knowledge and true belief, respectively. Thus, (c) and (c') are obtained from (b) and (b') via definitions (SV) and (NV), respectively. However, intuitively, one tends to accept (b) and (b'), without accepting (c) and (c'). This points to the fact that (b) is not necessarily equivalent to (c), and (b') is not necessarily equivalent to (c'). If this is the case, the definitions (SV) and (NV) do not achieve their goal of identifying sufficient conditions for someone's being ignorant of a given proposition.

\section{Possible criticisms}

In this section, we address some possible criticisms of the bowling ball argument, and present a version of the argument which is immune to these criticisms.

I. At least two points of the bowling ball argument can be challenged. First, the falsity of (a) and (a'). The ascription of a propositional attitude to an inanimate object is a categorical confusion, thus the propositions (a) and (a') are not false, but categorically senseless. In this sense, the negations of (a) and (a') are not necessarily true propositions. Second, in (b) and (b'), the ascription of not-knowing is also a categorical confusion. In light of these criticisms, it is not surprising that (c) and (c') are also categorically senseless. From this perspective, one cannot conclude that (b) is not equivalent to (c) or that (b') is not equivalent to ( $\left.c^{\prime}\right)$.

However, the bowling ball argument can be recast to meet this challenge.

Consider the following proposition:

(a") A bowling ball knows that $p$.

Proposition (a") is a categorical mistake or categorically senseless, thus

(b") It is not the case that a bowling ball knows that $p$, because knowledge is not ascribable to inanimate objects.

But for the Standard View, (b") is sufficient to conclude

(c") A bowling ball is ignorant of $p$.

Proposition (a") being a categorical mistake, (b") is obtained by detecting and correcting this mistake. In this way, (b") is not a categorical mistake, but a true proposition. However, (b") is clearly a situation of absence of knowledge and thus (c") can 
be obtained from (b") via the definition (SV). The same argument can be formulated, mutatis mutandis, for the New View.

II. Another possible objection can be put forward by taking into account Williamson's epistemology (see Williamson (2000)). Williamson thinks that ignorance is an absence of knowledge, knowledge is a mental state, and thus ignorance is an absence of a mental state. In this sense, it is true but pointless to ascribe the state of ignorance in (c) to inanimate objects. This objection dissolves the argument by accepting its paradoxical conclusion, but treating it as pointless.

However, the proponent of this objection should explain: first, what it means for an object to be ignorant of something (e.g., adding new clauses for how one can ascribe to an object the ignorance of $p$ or $\neg p$ ), and, second, what differentiates the ascription of ignorance to an inanimate object from the ascription of ignorance to an animate subject.

What is more, in the same vein, any counterintuitive application of a definition might be called true but pointless. For instance, according to the traditional analysis of knowledge, knowledge is defined as justified true belief. Famously, Gettier (1963) provides examples of justified true belief that intuitively do not constitute knowledge. Gettier's examples started an important epistemological debate on the definition and definability of knowledge. Following the objection à la Williamson, one could say that the traditional definition is correct and Gettier's examples are genuine cases of knowledge, but the ascription of knowledge in these examples is true but pointless. However, from our perspective, the mismatch between the definition and our intuition is not only a flatus voci, but points to a genuine problem.

III. One may say that the absence of knowledge or true belief is not complementary to the presence of knowledge or true belief. This would block the possibility of deriving (c") from (b").

However, a given state is either present or absent. It is not possible for a state to be present and absent at the same time, and neither is it possible for a state not to be present and not to be absent. Undoubtedly, the terms "presence" and "absence" are complementary, thus a definition in terms of the absence of some attitude or state should necessarily define something that is complementary to the presence of this attitude or state.

We take the bowling ball argument to show exactly that the main problem behind the definitions (SV) and (NV) is not that absence is not complementary to presence, but that ignorance is not complementary to knowledge or true belief. A further logical argument supporting this claim can be found in Kubyshkina \& Petrolo (2019). 


\section{Is ignorance a mental state?}

Another kind of objection to the bowling ball argument can be proposed. One could amend the initial definitions (SV) and (NV) by adding a clause specifying that $S$ is ignorant that $p$ if, and only if, $S$ is an epistemic subject. Such a specification is introduced by Nottelmann (2016). An epistemic subject in this case is "an entity capable of some sort of knowledge" (Nottelmann (2016), p. 35). Let us consider in what context this can be a reasonable assumption.

In contemporary epistemology there is an agreement on the fact that a state of knowledge can be attributed only to epistemic subjects. The reason for this is that only epistemic subjects can be in a mental state. Thus, if knowledge is a mental state or is constituted of a mental state ${ }^{1}$, knowledge can be ascribed only to epistemic subjects. One may be tempted to reason in a similar way in the case of ignorance: if ignorance is a mental state, it can be ascribed only to epistemic subjects. Thus, if ignorance is a mental state, the bowling ball argument can be rejected because the step from (b) to (c) (as well as from (b') to (c') and from (b") to (c")) is blocked. But can ignorance be considered a mental state?

In the literature, ignorance seems to be implicitly considered as a mental state without providing further analysis or justification. For instance, introducing the debate on ignorance as an excuse, Peels \& Blaauw (2016) write: "this debate concerns the relation between one's mental state of ignorance and one's actions" (p. 1). Le Morvan \& Peels (2016) also often refer to ignorance as a state. Let us now consider what are the conditions for a state to be a mental state.

Even though mental states are usually defined via some specific examples, some common features can be specified. For instance, Williamson (2000), p. 21, writes: "Paradigmatic mental states include love, hate, pleasure, and pain. Moreover, they include attitudes to propositions: believing that something is so, conceiving that it is so, hoping or fearing that it is so." Williamson stresses the fact that an epistemic subject's having an attitude to a proposition means that that subject grasps that proposition (Williamson (2000), p. 36). From this perspective, one of the conditions for a subject $S$ to be in a mental state $x$ with respect to proposition $p$ is to grasp $p$, or, in other words, to be acquainted with $p$. Thus, if ignorance is a mental state, $S$ 's being ignorant of $p$ means that $S$ has an attitude to $p$, and hense $S$ grasps $p$.

Now, let us consider three types of situations, which Peels (2019b) describes as genuine cases of ignorance for both the Standard View and the New View. ${ }^{2}$ Let $S$ be an epistemic subject, $p$ a true proposition, and $S$ a subject that neither believes $p$, disbelieves $p$, nor suspends judgment about $p$ :

- Unconsidered ignorance: $p$ is such that as soon as $S$ were to consider it, $S$ would believe it. 
- Deep ignorance: $p$ is such that $S$ would not believe $p$ upon considering it, even though $S$ could consider the proposition.

- Complete ignorance: $p$ is such that $S$ cannot grasp or entertain $p$.

In all these cases of ignorance, the agent does not consider $p$. In cases of unconsidered and deep ignorance, the agent is capable of grasping $p$ but is not actually in a position to have an attitude to $p$. The case of complete ignorance describes a situation where the agent is incapable of grasping $p$. These cases of ignorance are examples of ignorance that do not correspond to at least one of the features of a mental state, namely having an attitude towards a proposition. Therefore, considering these three situations as genuine cases of ignorance would contradict the assumption that ignorance in the definitions (SV) and (NV) is a mental state.

One may object that both Nottelmann (2016) and DeNicola (2017) say that ignorance can be ascribed to a subject that is capable of learning. This would block the possibility of ascribing ignorance to an inanimate object without necessarily embracing the view that ignorance is a mental state. However, the appeal to the ability to learn does not seem to be a sufficient specification. First, it seems that this restriction makes sense only if ignorance is considered to be a mental state, because the ability to learn also depends on being in a mental state. As a consequence, our previous argument against ignorance being a mental state applies. Secondly, being capable of learning $p$ implies either actually grasping $p$, or having the ability to grasp $p$. However, in the case of complete ignorance an agent neither actually grasps $p$ nor is capable of grasping it. Thus, even if one finds a way to reduce the applicability of (SV) and (NV) to only epistemic subjects capable of learning, without assuming that ignorance is a mental state, this would not solve the problem of the cases of complete ignorance.

To sum up, adherents of both the Standard View and the New View are faced with a dilemma. Either they accept the bowling ball argument and, thus, the fact that (SV) and (NV) do not provide sufficient conditions for the definition of ignorance, or they should exclude from their analysis cases usually considered as cases of ignorance. This second horn of the dilemma would lead to the deeper and seemingly paradoxical problem of classifying and analysing unconsidered, deep, and complete ignorance as not being cases of ignorance.

\section{Conclusion}

We put forward the bowling ball argument to show that both adherents of the Standard View and the New View are committed to making a categorical mistake in attributing ignorance to inanimate objects. We defended the argument from some 
possible criticisms and concluded that neither definition (SV) nor definition (NV) identify sufficient conditions for ignorance. The argument also raises the fundamental question of whether ignorance is a mental state. We argued that the answer to this question is negative and, consequently, the bowling ball argument presents a genuine challenge to (SV) and (NV).

A lesson that can be learned from this is that the main difference between the Standard View and the New View lies in accepting or rejecting absence of true belief as a necessary condition for ignorance. From this perspective, the Standard View does not seem to be a very informative position as it simply claims that ignorance is incompatible with knowledge, a point that is not disputed by adherents of the the New View. However, the New View seems to provide some further characterization by establishing a relationship not only between knowledge and ignorance, but also between ignorance, truth and belief.

\section{References}

DeNicola, D. R. 2017. Understanding ignorance: the surprising impact of what we don't know. Cambridge: The MIT Press.

Driver, J. 1989. The Virtues of Ignorance. The Journal of Philosophy 86(7): 373-384.

Fields, L. 1994. Moral Beliefs and Blameworthiness. Philosophy 69(4): 397-415.

Gettier, E. L. 1963. Is Justified True Belief Knowledge? Analysis 23: 121-123.

Goldman, A. I. 1986. Epistemology and Cognition. Cambridge, MA: Harvard University Press.

Goldman, A.I.; Olsson, E. J. 2009. Reliabilism and the Value of Knowledge. In: A. Haddock, A. Millar, and D. Pritchard (eds.), Epistemic Value, p.19-41, Oxford: Oxford University Press.

Guerrero, A. A. 2007. Don't Know, Don't Kill: Moral Ignorance, Culpability, and Caution. Philosophical Studies 136(1): 59-97.

Kubyshkina, E.; Petrolo, M. 2019. A logic for factive ignorance. Synthese, S. I.: Knowing the Unknown: Philosophical Perspectives on Ignorance, Online First, p. 1-12, DOI: 10.1007/s11229-019-02440-1.

Le Morvan, P. 2011. On Ignorance: A Reply to Peels. Philosophia 39(2): 335-344.

Le Morvan, P. 2012. On Ignorance: A Vindication of the Standard View. Philosophia 40(2): 379-393.

Le Morvan, P. 2013. Why the Standard Conception of Ignorance Prevails. Philosophia 41(1): 239-256.

Le Morvan, P.; Peels R. 2016. The Nature of Ignorance: Two Views. In R. Peels, M. Blaauw (eds.), The Epistemic Dimensions of Ignorance, p.12-32. Cambridge: Cambridge University Press.

Nagel, J. 2013. Knowledge as a Mental State. Oxford Studies in Epistemology 4: 273-306.

Nottelmann, N. 2016. The Varieties of Ignorance. In R. Peels, M. Blaauw (eds.), The Epistemic Dimensions of Ignorance, p.33-56. Cambridge: Cambridge University Press.

Peels, R. 2010. What is Ignorance?. Philosophia 38(1): 57-67. 
Peels, R. 2011. Ignorance Is Lack of True Belief: A Rejoinder to Le Morvan. Philosophia 39(2): 344-355.

Peels, R. 2012. The New View on Ignorance Undefeated. Philosophia 40(4): 741-750.

Peels R.; Blaauw, M. 2016. Introduction. In R. Peels, M. Blaauw (eds.), The Epistemic Dimensions of Ignorance, p.1-11. Cambridge: Cambridge University Press.

Peels, R. 2019a. Exploring the Boundaries of Ignorance: Its Nature and Accidental Features. Social Epistemology Review and Reply Collective 8(1): 10-18.

Peels, R. 2019b. Asserting Ignorance. In The Oxford Handbook of Assertion. S. Goldberg (eds.). DOI: 10.1093/oxfordhb/9780190675233.013.25.

Williamson, T. 2000. Knowledge and its Limits. Oxford: Oxford University Press.

van Woudenberg, R. 2009. Ignorance and Force: Two Excusing Conditions for False Beliefs. American Philosophical Quarterly 46(4): 373-86.

Zimmerman, M. J. 1988. An Essay on Moral Responsibility. Totowa, N. J.: Rowman and Littlefield.

\section{Notes}

${ }^{1}$ There are epistemologists who disagree that knowledge is a mental state (for an overview, see Nagel (2013)). These epistemologists consider that knowledge is a composite of belief (that is, a mental state) and non-mental factors.

${ }^{2}$ Peels (2019b) provides specific examples for each of these situations.

\section{Acknowledgements}

The authors would like to thank for useful comments on the material of this article Otávio Bueno, the anonymous referees of Principia and the audience of $11^{\text {th }}$ Principia International Symposium "The quest for knowledge" and of Munich Center for Mathematical Philosophy seminar. The authors gratefully acknowledge the support of São Paulo Research Foundation (FAPESP) through the project Auxílio à Pesquisa - Jovem Pesquisador n. 2016/25891-3. The work of Ekaterina Kubyshkina is supported by the São Paulo Research Foundation (FAPESP), grant 2018/25501-6. The work of Mattia Petrolo is partly supported by National Council for Scientific and Technological Development (CNPq) through the project Universal/Faixa A, n. 433781/2018-1. 